\title{
Marketing Strategy of Pay Channels
}

\author{
Fanbin Zeng ${ }^{1} \&$ Xiaojing Yang ${ }^{1}$ \\ ${ }^{1}$ College of Journalism and Communication, Jinan University, Guangzhou 510632, China \\ Correspondence: Fanbin Zeng, College of Journalism and Communication, Jinan University, Guangzhou 510632, \\ China. E-mail: zengfanbin@vip.sina.com
}

Received: July 29, 2012 Accepted: August 8, 2012 Online Published: November 30, 2012

doi:10.5539/ass.v8n15p46 URL: http://dx.doi.org/10.5539/ass.v8n15p46

This Project was financed by 2012 General Foundation of the Twelfth Five-Year Plan of Guangzhou Philosophy and Social Science Research (Grant Number; 2012YB31; Grant Title; Effect of Time Spent Online and Patterns of internet use on Real-life Political Participation: Based on Empirical Study on Internet Users in Guangzhou)

\begin{abstract}
Pay Channels not only need to improve the quality of their content, but also need to focus on marketing strategy. To develop Pay Channels in China, we not only need to improve the content of the TV programs, but also need to focus on the marketing strategy. So far, we have two main approaches of marketing in China. One is being operated by integration platform; the other is by the Channel itself. Pay channels are not developed so well in China. In this paper, we are going to discuss on the existing problems of pay channels in China and try to find out the effective ways to carry out marketing strategy of pay channels. To improve the situation of pay channels in China, we might take the following measures: 1) Pursue different kinds of sales approach. 2) Provide Free Preview to Expand the Scope of Publicity. 3) Lower charging fee. 4) Establish a perfect customer service system.
\end{abstract}

Keywords: pay channels, marketing strategy, consumer-centered

\section{Introduction}

Pay Channels not only need to improve the quality of their content, but also need to focus on marketing strategy. So far, there are two main ways of marketing in China. One is being operated by integration platform; the other is by the Channel itself. The integration platform regards the platforms which have been integrated as a whole, with unified package, unified image, unified publicity and unified selling. The advantage of integration platform is that it can reduce the investment in operating and also lower the admission fee, while the disadvantage of it is that it will lose the initiative and the flexibility, besides, it will have to pay for the agency fee. At the beginning of the promotion, it is one disaster after another when the poor Channels have to pay such a great amount of money for the admission fee. However, it is more personalizing that the Channel does the promotion by itself. The advantage of promotion by itself is that the channel has initiative in marketing, and it has more flexibility in choosing network operating institute. Besides, the channel doesn't need to pay for the expensive agency fee. In 2003 , the largest part of total revenue was spent in program, which occupied $57 \%$ of the operating cost; next is marketing expenditure, which is $14.3 \%$ of the operating cost; The cost from management fee of the subscribers came third, which is $12 \%$. These three main expenditures are the keys to the success of pay TV, from which we can see the importance of marketing. So, we should put high value on marketing if we want to develop pay channels in China.

It is of great important to formulate a flexible marketing strategy, set about marketing, attract more subscribers for pay channel and attain a relatively steady user base by consistently providing qualified services. Meanwhile, we should consistently attract more new users and finally set up the operation pattern which is accepted by the market. Only in this way can we change the audience's fixed ideas of watching TV without pay and develop a habit of watching pay channels. The so-called marketing of pay channels is composed of the combining of the video and audio, package, binding and service design, pricing, and planning and implement for promotion and distribution. The purpose of marketing is to achieve the exchange of personal goal and organization goal. To analyze the marketing strategy of pay channels, we should analyze the relative theory of marketing first. 


\section{Relevant Theory of Marketing}

The marketing theory in America has undergone a conversion form 4P marketing theory to 4C marketing theory. The production and operation of the branded television programs can use this conversion for reference. The so-called $4 \mathrm{P}$ refers to product, place, price and promotion. $4 \mathrm{C}$ refers to consumer, convenience, cost and communication. The former emphasizes the features of the product, while the latter focuses on discovering and catering for the need of costumers.

\subsection{The Marketing Theory of $4 P s$}

The Marketing Theory of 4Ps was put forward in 1960s, with the establishment of Marketing Mix Theory. The term of marketing mix was first mentioned by NeilBorden in his inaugural address of American Marketing Society in 1953. Marketing mix means that the market demands was effected by variable of sales or marketing factors at some level. In order to get the market response, we should make the most efficient combination of those factors to satisfy the market demand and get the maximum profit.

E.Jerome McCarthy first summed up four basic combination strategies of corporation marketing in his book Basic Marketing, which was 4P's Theory: Product, Price, Place and Promotion. As these four words begin with P, along with the word strategy, we call the combination "4P's" for short. In 1967, Philip Kolter further confirmed marketing mix with 4Ps at its core in his hot-selling book Marketing Management: Analyst, Planing and Controli(Note 1)-Product: focus on developing new products with special selling point, putting the function of the products in the first place. Pricing: draw up different pricing strategies according to different marketing positions; focus on brand gold content. Place: Corporations do not directly contact with consumers, but focus on developing distributors and establishing selling network, which help build up the connection between corporations and consumers. Promotion: Corporation should focus on stimulate consumers by changing the selling behaviors, increasing sale by short-term behaviors, like buy one take one, build a good atmosphere and so on, to increase the sales by attracting other brand's consumer or stimulating advance consumption.

\subsection{C Marketing Theory}

In the business world which regards the consumers as its core, the manufacturer confronts with the most challenging task: this is a personalized society, where there are different kinds of consumers. With consumer-centered age coming, the traditional 4P marketing theory is out of stage. Therefore, scholars of marketing come up with new ideas of marketing. Mr. Roterorn put forward new ideas of 4P theory in Commercial Time in 1990, which is 4C theory. It emphasizes that the corporation should put the consumers' satisfaction in the first place, which that that the products should cater for the consumers' demand and lower the purchasing cost for consumers. When developing a new product, purchasing power should be taken into account. Besides, corporation should provide convenience to customers when they are buying. Finally, corporation should have efficient consumer-oriented communication with their clients.

4C: 1) Customer's needs and wants; 2) Cost and Value to satisfy consumer's needs and wants; 3) Convenience to buy; 4) Communication with consumer. Some people even think that the marketing in the new era should replace $4 \mathrm{P}$ with $4 \mathrm{C}$. Still, some scholar believed that the putting forward of " $4 \mathrm{C}$ " made the basic precondition of marketing strategies more explicit. From the operation level, we should relied on the marketing activities represented by " $4 \mathrm{P}$ ".

That is to say " $4 \mathrm{C}$ " deepens the " $4 \mathrm{P}$ " instead of replacing it. In fact, " $4 \mathrm{Ps}$ " is still the concisest explanation of marketing mix. 4Ps and 4Cs are complementary. For example, "Customer" refers to costumers replacing "Products", which means that we should study the demand of our customers first and design, produce and sell our products and service which our customer want next.; Cost refers to "Cost" replacing "Price", which means that we should meet the requirement of the demanding cost of our clients fist and then draw up the pricing strategy.; Convenience refers to replacing "Place" by "Convenience", which means that when drawing up the distribution strategy, we should offer as much as convenience to our customers. Communicationg refers to "Communication" replacing "Promotion", which means that promotion is linear communication while communication is bidirectional.

\section{Pay TV should Establish Consumer-centered Marketing Concept}

Consumer-centered idea is a very common appeal in other business areas, but it is just adopted in the TV area. Digital Pay Channels are newly born, which make the TV media change from disseminator-oriented to receiver-oriented, fully reflecting the idea of people-oriented.

In the industrial value chain of digital pay channel, the contents became the products, which can make revenue from the subscribers. By paying for the digital pay channels, users got the decision-making power over watching 
TV. The needs of costumers are the original driving force of the development of Pay TV. To the TV operators, what they focus change from advertisers to consumers. They have connection with consumers and make contact with them. The relationship between operators and users are not simply the broadcasting relationship only, instead, it is a close relationship between supply and demand. The free Channel depends on the scale, focusing on the group value, but Pay Channels depend on thorough service, taking individual value as importance. So, Pay Channels should better study the potential clients in the process of producing programs and marketing.

Since HBO began broadcasting, it has been maintaining operation by charging subscribers. What HBO pursues is a very complex communication effect which is that it never intends to please the majority audience, but try to find the different favor of the different types of subscribers. For example, the audience rating of Sex and the City is not so high, but it appeals to the female audience - the rate of female subscribers is $40 \%$ of the total subscriber of total HBO subscribers. So, what the executives concern about is the overall satisfaction of their subscribers, which means that they don't care about how many audiences are watching their programs, but concern about the rate of the amount of audience who appreciate the program. This idea exactly reflects the user-centric communication and market ideas, and it is the base of the future success.

When drawing up the marketing strategies of the paying channels, it should really be consumers-centric. The network operator should specially focus on the features of consumer psychology, adapting the operating strategies to the change of consumers. Only by consistently providing high quality and personalized service can we maintain and improve the consumers' loyalty to the pay channels. If not, pay channels will lose their consumers.

Being users-centric, pay channels should consider the following:1) the demand and desire of consumers; 2) the cost of satisfying consumers; 3 ) convenience of purchasing; 4) communication with audience. Only the strategies based on these factors can they satisfy the demand of our customers. First-class service and marketing strategies are the key factors of the pay TV, because pay TV is led by consumers. That's why pay TV is different from public TV. Compared to the pay TV, public TV channels are simpler. Pay TV is nothing but producing good programs and selling commercial time, which does not have a direct relationship with consumers. Besides, the number of public channels is limited, while pay channels may have hundreds. Users are willing to pay not only because of the attractive programs but also the good quality services.

The operators of pay TV should try their best to service their customers. Only by this can they win the customer group. It is because the direct relationship between the operator and customers that Bsky B company win the reputation of having the best subscribers management system and most effective marketing system in the field. The running revenue of BskyB company increased $11 \%$ in 2003, and the turnover rate of their users was lower than $10 \%$, which was the lowest in the world. This fact showed that users buy the service and the program contents of BskyB.

There are 3,500 staff in Call Centres of BskyB company. They answer hundred thousands of phone calls from users and potential customers. It is those normal frontline staff answering phone calls.

In the perspective of marketing, maintaining old customers is as important as develop new costumers, but the cost of maintain old customers is much lower than develop new customers. As a new way of attracting customers, BskyB had new tactics in 2004, which is bringing out intelligent VIP card. This VIP card which inserts into the set-top box can distinguish and record the user's habits of watching TV. If the user dotes on a certain channel or a program or takes part in any promotion program of the company, he/she can save points. When the points reach a certain level, the user can watch the pay TV program for free. BskyB make some improvement of the set-top box to make this tactic possible (Note 2).

\section{The Pay Channels' Marketing Experience in China}

The pay channels marketing in our country has developed a industrial chain including distributors, integrated operator, wired network operator and users. Channels give the Pay Channels they made to the integrate operators, and then operators pass them to the wired network operators who finally deliver them to the users' home through local wired network. The revenue will be allocated proportionally to these three organizations according to the agreement they have reached. Pay channels allocation proportion is 5:4:1 so far, wired network company 50\%, program producing company $40 \%$ and operator $10 \%$.

In this Chain, integrate operator plays a very important role. Its main responsibility is to respectively deliver pay Channels to local network company and have relative agent marketing.

Up till now, there are two main promotion ways. One is to be promoted by media agency, the other is to be promoted by the channel itself. The Center Program Platform will regard the integrate channels as a whole, with 
unified package, unified image, unified promotion, joining all forces. In the 2004 CCBN fair, Centre Program Platform set up a big pay channels exhibition area, promoting pay channels to the network operators from all over the country.

Pay channel of China Centre TV started in Sep.1, 2004, pricing at 58 yuan per month. 58 yuan per month is the price of the package of six channels. In September, 2004, the centre digital TV integrate platform China DTV Media Inc. Ltd started business operating. Within 5 months, it developed 120 thousand users, earning millions, which took $95 \%$ market share of pay TV in the whole country. At the beginning of 2005, China DTV Media Inc. Ltd packaged 14 channels to sell, pricing at 28 yuan per month and developed the current core products of the company called CCTV Basic Package. China DTV Media Inc. Ltd carried out a marketing research and found that 30 yuan per month was accepted by audience

China DTV Media Inc. Ltd has designed low, middle and high calss products according to different markets and target groups. CCTV Basic Package has been the core product. The DTV platform has developed from 14 channels to 40 channels. As the quantity and types of the channels are increasing, the single product structure can't meet the demand of the market. New CCTV Basic Package increased the quantity of the channel, improved their quality, and perfect the program content to provide a basket solutions to the family which use digital pay TV, covering all-around aspects family life to let every family member can find his/her favorite program. China DTV Media Inc. Ltd adopted "one-more strategy", which means the competitive advantage of their products is that there is at least one more channel in the package compare to its competitors to ensure the highest cost effectiveness.

For the First Theater, Golf and Tennis and National Defense and Military those high quality programs, China DTV Media Inc.Ltd applied the respective-selling strategy, not packaged with other channel in principle. Single-channel selling strategy promoted the sales of Basic Package.

To keep the important audience with the specific purpose of watching certain program, China DTV Media Inc.Ltd adopts different developing measures according to different levels of audience, and try to provide mature channels and service to the customers as soon as possible. For those conformity audience, DTV Media Inc.Ltd tried to change their idea by opening the guiding channels or present them the a certain period of time of free programs.

To have better marketing, China DTV Media Inc.Ltd have a perfect feed back way. It started a hot line (010-51925192) at the beginning and cooperated with CCTV, using $7 * 24$-hour answering calls service. The service call makes solution, solve their problem and record the feed back from customers. To analyze the feed back does good to perfect the arrangement of programs and marketing strategy as well. Service Call makes audience feel the human-oriented service of China DTV Media Inc. Ltd, which increases users loyalty to it (Note $3)$.

The marketing of pay channels can also be conducted via internet like weibo. Weibo is a brand-new socialized media, with high-speed of communication, low cost of operation, flexibility and interactivity. Its birth bring opportunity to the development of TV. On the one hand, Weibo provide TV media with immediate and a wide range of information sources. On the other hand, Weibo can conduct butterfly effect, which can deliver a topic to every terminal access over night, extending the media brand in the internet.

\section{The Existing Problems and Development Strategy of the Pay Channel in China}

The wired TV operation service provider in our country is local wired network company. The marketing degree in our country is low because of the system and other factors. The extensive model of traditional wired TV business made the network operator form inertia thinking that only charge when the signal arrives at home. The local wired network company only takes the responsibility of charging but ignore the importance of market. The local wired network company was lack of experience and ability in marketing and didn't realize marketing and service can create more space for profits. The weakness existing in sectors of marketing sales has been the trouble of the development of pay channels. So, here we put forward the directions of the development of pay channels in the future:

\subsection{Pursue Different Kinds of Sales Approach}

First, operator packages the pay channels according to their types, as thus can lower the overall cost for users. However, the fact is that this approach takes away the flexibility for users to choose the channels they like. National Broadcast and TV General Bureau pointed out that the add-value service like pay TV, dibble seeding, TV shopping, TV business and exchange TV can cater for the different demand of audience. Personalized marketing service should be based on the marketing economy principles. Users should be allowed to choose on 
their own. Obviously, it is the user who can decide what channels they want to pay for. In HK China, the charge model is "basic service + extra charge + combined package". In England, Sky Broadcast who is in charge of digital pay TV business packaged channels, including family package, fashion mixture package and so on. Each package can be sold separately or sold with the extra-charge channels. In the foreign country, pay channels adopt different kinds of charging approaches. Most of the pay TV make profit by commercial and very low subscribing fee, which are called "mini-pay". Besides, those channels are usually sold with the channels with the same price (Note 4).

User can choose the subscribing way from the menus. Usually, the price of those pay channels ranges from $\$ 10$ per month to $\$ 15$ per month. However, the other channels like sports channel and adult channel are much more expensive, which are about $\$ 50$ per month. Some channels are sold by package, in which there are 20 to 40 channels, charging 16 pounds per month. If the user wants to buy one more children package, he/she only have to pay another one pound, which means that two package cost only 17 pounds. The more you buy, the more discounts you have.

\subsection{Provide Free Preview to Expand the Scope of Publicity}

The publicity of pay channel has always been the weakest sector. According to the survey, the cognition index of publicity is the lowest, which is only 91.5. Up till now, except for digital pay TV is sometimes mentioned in the news, it hardly appears in any publicity of communication media. Besides, being as the sale access, local wired network company has rarely propagated pay channels. That's why users don't know much about pay TV. To improve the situation, pay channels should give publicity in different ways. On the one hand, they should let audience know them more, on the other hand, they should build up a brand-new image to their users. Only in this way can they develop better and attract more audience. What pay TV has to do now is win trust from audience by positive attitude, good service and variable choices. Those efforts will help users develop a habit of watching pay TV. Gradually, Pay TV will be the first choice of audience. When conducting propaganda, users' opinions, of course, come first. Dongguan Broadcasting and TV Network Development Co.Ltd conducted a award survey activity of "My Favorite Pay Channel" in March, 2003, in which there 700 lucky audience win the awards with a total value of 245 thousand. The leader of operation center named Lai Jianhong said, " Interviewees provided us a lot of valuable opinions in the survey which would help us a lot in decide what kind of TV program to purchase and developing marketing strategies." Those marketing research can help them to get to know the market and real demand of consumers. Besides, it extends the influence of pay channels.

For pay Channels, free preview is the best way of publicity. Pay TV in the foreign country usually use this way to attract customers. Free preview usually used in the wired television provides a period of time for audience to watch the pay channels for free. Free preview was first adopted by 14 operators of HBO in New York and Pennsylvania in 1973(the second year after HBO was born). Audience's turnover rate of HBO was very high, as audience had been tired of watching the pay TV programs after they watch it in preview for free. HBO was bothered by the result and decided to do something to improve the situation. When HBO give publicity in Massachusetts, it began to allow subscribers watch channel 3 for free. After a month, it shifted to channel 6 providing audience with the same service. Free preview service is quite welcomed by audience and won a lot of subscribers. After that, HBO and other pay TV began to provide free preview service to attract subscribers. Those free preview service usually last for 3 days, from Friday to Sunday (in recent years, it is from Friday to Monday). Some pay channels even provide five-day free preview service. The purpose of free preview service on weekends is to attract people who need to go to work or go to school in weekdays to subscribe pay TV. However, free preview hasn't delete any content, including some violence, pornography and dirty language, which may be watched by kids sometimes.

Pay Channels in foreign countries let famous host propagate their preview service in 1980s. Many wired TV companies provided more attractive stimulation approaches. For example, Cox Communication Company often gives awards to their audience who receive free preview service.

However, the connotation of free preview has been changed since higher level of digital TV service came up in recent years. Many digital pay TV companies have just stop the free preview service for promoting their pay channels because those preview services have been stopped putting in the wired TV or satellite TV. There are many systems are connected with pay channels, so pay channels are compete for authority to provide those services. Some dibble seeding channels or pay sports channels provide free preview service sometimes and may last for one to two weeks. Recently free preview service is provided in the form of internet short video. There is 15 minutes preview of HBO's great work Game of Thrones on line. 


\subsection{Low Charging Fee, Commercial and Other Revenues}

In additions, pay channels should consider lower their price to attract as many as users. Compared to 17RMB per month of Guangdong wired TV, 36RMB per month for digital pay TV is too expensive. Most of the wired TV audiences think that they can't afford it. Before we ignore the influence of price, keep pricing 36RMB per month. Though there have been some really excellent channels like HBO, Ifeng Information, Female Fashion, Goff, Soccer, World Geography and so on.

Of course, if we decide to lower the price, we should consider about broadcast some professional commercials which are related to the content of the channel. According to a survey conducted by CCTV, audiences prefer to watch commercial rather than pay for TV program. $75.2 \%$ audiences agreed that there should be commercial rather than have they pay for TV program. This shows that most of the audiences are afraid that they should pay more for watching TV.

Nowadays the pay channels have been made a breakthrough and their profit model doesn't rely on TV fee but extend to the other aspects, including the followings: 1) TV fee. Acting as a content integrators and content supplier, pay channel shares revenue with all-level network companies. This is the main part of their revenue. 2) Sales revenue of the TV programs: The TV programs of pay channels have a high degree of specialization and they are able to have secondary development, being sold to other broadcast platform. As far as I concerned, Beautiful Make-up Channel is planning to sell itself to network television, mobile phone television, outdoor television and public transport television. This make the channel broadcast have a wide range of development. 3) Deriving revenue: deriving operation is an important revenue of pay channels. The pay channels have high degree of specialization and are easy to form a professional platform, building up a professional brand. Deriving operation can be easily developed based on this. According to the introduction of the marketing manager of Beautiful make-up channel, the channel has been connected with many products and manufacturers. They can have all kind of creative activities for corporations, including model agent and image spokesperson recommendation, holding release conference for garments, relaying fashion show, brand promotion and so on.

\subsection{Establish a Perfect Customer Service System}

Customer service system is a system with coordination of staff, business schedule technology and strategies. It provided a suitable way for getting organization resources. It creates customers value and corporation value by mutual communication way. Costumer service system develops around service, with the core conception of satisfying customers. By winning satisfaction and loyalty of customers, it promote the win-win exchange and reach the goal of marketing performance. Meanwhile, it creates a favorable opinion environment and government policy by providing good service and strengthening public image of the company, thus to achieve a long-term development. So, pay TV can perfect its customer service system in the following steps:

(1) Set up 24-hour free service line, which is Call Center. Answering phone calls from customers at anytime and make solution for their problems. Besides, those customer service officers should be supervised in real time to ensure the quality of service. Increase the number of service officer to increase the answering rate of phone call. We should deal with all the customer complaint seriously.

(2) Build up a perfect operations support system, which also be named BOSS. It is a very important task in the area of wired digital TV. Radio and television industry is originally for broadcasting, which is point to plane, so we don't care about the users' situation. After digitalizing, we found it important to provide service to customer according their demand (Note 5). The origin of Operations Support System is from telecommunication, because telecommunication has a very complex charging procedure. This system is used by communication operation in recent years. The first phase project has been finished and there have been obvious effects on analysis of user and customer detainment. As per the experience of the telecommunication operators, digital TV operator should establish operation analysis system, finding out users' demand by establishing users' data base.

(3) Establish and perfect the consumer service system, including "guaranteed satisfactory solution system", "time-limit service system", "recall system" and so on.

(4) Establish online enquiries system. Enhance the service function of the internet. Take Shenzhen Tianwei video website as an example which can offer most of the daily service.

(5) Send repairman to provide door-to-door service and improve the quality of them.

(6) Return visit for users. This work should be done regularly according to the refection the users' data base. Return visit can be done through the way of phone call, door-to-door visit, email or message. Return visit represents the personalized service and it is a effective way of user survey. The purpose of return visit is to show that pay channels attach important to their users. Besides, they can promote their new channels and business by 
return visit. What more, they can also get the feed back from audience effectively and efficiently. (Pay channels should improve their TV program according to the feed back from users. Meanwhile, they should know the shortages in marketing and service on their own and find solution to overcome their shortages in time. They should also report the reason of existing shortages to the department of marketing or sales, so that they could have prompt improvement.

\section{References}

Chen, C. H., \& Zhang, Y. T. (2001). Strategy of Developing Digital Pay Channel Users. Journalisms, 8.

Du, G., \& Wang, Z. Y. (2009). Analysis the Pricing Features of Digital Pay TV—Based on Guangdong Wired Network. Wired TV Technology, 10.

Huang, S. M., Zhou, Y., \& He, H. B. (2005). New Operation Direction of China TV Media Industry. Beijing: China Communication University Press.

Liu, J. M. (2003). A Sampling Survey of the national Audience in 2003. TV Studying, 4, 10.

Yang, J. H. (2008). New Media Convergence and Digital TV. Beijing: Qinghua University Press.

Zhang, X. Y. (2006). The Key to the Success of American HBO. Teenager Journalists, 5, 76.

\section{Notes}

Note 1. http://wiki.mbalib.com/wiki/4Ps\%E8\%90\%A5\%E9\%94\%80\%E7\%90\%86\%E8\%AE\%BA

Note 2. http://www.xinhuanet.com "Broadcasting and Video in China", 2005-07-29

Note 3. http://www.sarft.net/a/33245.aspx

Note 4. Information from http://www.sky.com

Note 5. Xie Jinhui , "Wired Digital TV", on $17^{\text {th }}$ ccBN2009 BBS. 